\title{
PAP1 signaling involves MAPK signal transduction
}

M. Ferrés-Masóa ${ }^{\mathrm{a}}$, N. Sacilotto ${ }^{\mathrm{b}}$, G. López-Rodas ${ }^{\mathrm{b}}$, JC. Dagorn $^{\mathrm{c}}$, JL. Iovanna $^{\mathrm{c}}$, D. Closa $^{\mathrm{a}}$, E. Folch-Puy ${ }^{\mathrm{a}}$

${ }^{\text {a }}$ Department of Experimental Pathology, IIBB-CSIC-IDIBAPS, CIBERehd, Barcelona, Spain.

${ }^{\mathrm{b}}$ Department of Biochemistry and Molecular Biology, University of Valencia, Spain

${ }^{\mathrm{c}}$ Centre de Recherche INSERM U.624, Stress Cellulaire, Marseille, France

IIBB-CSIC: Institut d'Investigacions Biomèdiques de Barcelona - Consejo Superior de Investigaciones Científicas; IDIBAPS: Institut d'Investigacions Biomèdiques August Pi i Sunyer, CIBERehd: Centro de Investigación Biomédica en Red de Enfermedades Hepáticas y Digestivas

Address for correspondence:

Dr Emma Folch-Puy

Experimental Pathology Department, IIBB-CSIC-IDIBAPS

c/ Rosselló 161, 7º, 08036 Barcelona, Spain.

Tel (34) 933638307

Fax (34) 933638301

E-mail: efpbam@iibb.csic.es

Running title: MAPK signaling activation by PAP1 


\begin{abstract}
Pancreatitis-associated protein 1 (PAP1) belongs to the Reg family of secretory proteins. Several important biological roles have been attributed to PAP1 but the signaling pathways activated by this protein remain only partially understood. Here, we describe the intracellular pathways triggered by PAP1 in a pancreatic acinar cell line. Taking advantage of the fact that PAP1 induces its own transcription, we performed ChIP assays to analyze the recruitment of transcriptional factors on its promoter. Our results show that PAP1 increased the transactivation activity of papl and the binding on its promoter of the nuclear factors C/EBPß, P-CREB, P-ELK1, EGR1, STAT3 and ETS2, which are downstream targets of MAPK signaling. p44/42, p38 and JNK MAPKs activity increased after PAP1 treatment. In addition, pharmacological inhibition of these kinases markedly inhibited the induction of papl mRNA. Taken together, these results indicated that the mechanism of PAP1 action involves the activation of the MAPK superfamily.
\end{abstract}

Key words: PAP1, MAPK, Transcriptional Factors, AR42J, Chromatin immunoprecipitation, RNApol ChIP. 


\section{Introduction}

Pancreatitis-associated protein 1 (PAP1) is a C-type lectin originally identified as a pancreatic secretory protein, not expressed under physiological conditions but strongly overexpressed during acute pancreatitis [1]. Its expression is actually not restricted to the pancreas and has been linked to a variety of diseases including inflammatory bowel disease [2], Alzheimer's disease [3] or some types of cancers such as hepatocellular carcinoma [4], pancreatic adenocarcinoma [5] and colorectal carcinoma [6].

PAP1 is a 175 aminoacid long polypeptide containing one carbohydrate-binding domain (CBD) linked to an N-terminal sequence, part of which is cleaved during its maturation and secretion [7]. This protein was the first identified member of a family of proteins that comprises lithostatine and several isoforms of PAP sharing important sequence similarities [8]. Data from experimental acute pancreatitis showed that the secretory patterns of these proteins are coordinated, with a peak of expression in pancreatic tissue or juice 24 hours after the induction of acute pancreatitis by cerulein [9]. However, the levels and the expression pattern of these proteins are different, suggesting that these isoforms do not substitute one another but may have different functional properties. [10].

PAP1 has been described in different species under different names: it was called p23 protein when secreted by rat pituitary cells [11], HIP/PAP when reported in hepatocellular cancer [4] or Reg2 when expressed in regenerating motor neurons [12]. Also, PAP1 was shown to be involved in several biological functions, sometimes apparently unrelated. In pancreatic acinar cells, overexpression of PAP1 increases resistance to apoptosis [13, 14]. PAP1 acts as a growth factor promoting cell proliferation in hepatocytes [15] and motor neurons [12]. Moreover, PAP1 exhibits mitogen activity on Schwann cells and promotes nerve regeneration [16]. It also promotes intestinal epithelial cell growth [17]. A function linking cell migration and cell adhesion to extracellular matrix has also been proposed for PAP1 [18, 19]. 
Widening the PAP1 range of functions, our group demonstrated an anti-inflammatory role for this protein in agreement with its strong induction during the course of inflammatory disease such as pancreatitis, Crohn's disease and ulcerative colitis. In a rat model of acute pancreatitis, the infusion of anti-PAP1 antibodies worsened the pancreatic inflammatory response [20]. In the same study, PAP1 treatment prevented TNF $\alpha$-induced Nuclear Factor kappa B (NFkB) activation in macrophages. This protective function of PAP in acute pancreatitis has been confirmed using antisense PAP oligonucleotides in order to block the expression of all three isoforms of PAP [21]. As well, Gironella et al. corroborated the antiinflammatory role of PAP1 in vivo in a PAP1-deficient mice model [22].

Although a number of studies have focused on the physiopathological significance of PAP1, little is known of the signal transductions triggered by PAP1. Recent data have shown that PAP1 inhibited the inflammatory response through a JAK/STAT3 dependent mechanism [23]. Nevertheless, PAP1 effects are not entirely explained by the activation of JAK/STAT3 as it is known that signals transduction usually involves an intricate and complex network of interactions between several signaling pathways. The purpose of this study was to identify the intracellular signaling pathways induced by PAP1. Taking advantage of the fact that PAP1 induces the expression of its own gene, we performed a Chromatin Immunoprecipitation assay (ChIP) to correlate transcriptional factor recruitment to the papl promoter with the signaling pathways triggered by PAP1. Our results showed that PAP1 increased the transactivation activity of the nuclear transcriptional factors associated with the MAPK superfamily. 


\section{Materials and Methods}

\section{Reagents}

All culture supplies were obtained from Invitrogen (Carlsbad, CA). Reagents for SDS-PAGE, blotting paper and nitrocellulose membranes were from BioRad (Hercules, CA). Antibodies against P-p38, P-p44/42 and P-JNK were supplied by Cell Signaling Technology (Beverly, MA). Antibodies against $\beta$-actin, C/EBP $\beta$, P-CREB, P-ELK1, ATF2, EGR1, c-JUN, STAT3, NFkB (p65), ETS2, ATF3, SRF and RNApol II were supplied by Santa Cruz Biotechnology (Santa Cruz, CA). The secondary antibodies linked to horseradish peroxidase were purchased from Sigma (St. Louis, MO). Specific inhibitors for each MAPK families: SB203580 (p38 MAPK inhibitor), PD98059 (p44/42 inhibitor) and JNK Inhibitor II (JNK inhibitor) were obtained from Calbiochem (Nottingham, UK). Recombinant human PAP1 was produced in the yeast Pichia Pastoris according to the recommendations of the manufacturer by Dynabio SA (Marseille, France). The PAP1 ELISA used to quantify PAP1 (PancrePAP) was obtained from Dynabio SA (Marseille, France).

\section{Cell culture}

Rat pancreatic acinar cells (AR42J) were grown in monolayers until 70-80\% confluence in a Dulbecco's Modified Eagle's medium supplemented with 10\% Fetal Calf Serum 'Gold' (PAA Laboratories, Pasching, Austria), $2 \mathrm{mM}$ L-glutamine, 100U/mL penicillin and 100 $\mu \mathrm{g} / \mathrm{ml}$ streptomycin (Sigma, St. Louis, MO) at $37^{\circ} \mathrm{C}$ in a humidified atmosphere of $95 \%$ air, 5\% CO2. Cultures were split every 3 days by trypsinization with $0.1 \%$ trypsin (Sigma, St. Louis, $\mathrm{MO}$ ) in $\mathrm{Ca} 2+/ \mathrm{Mg} 2+-$ free PBS containing 0.9 mM EDTA.

\section{Chromatin immunoprecipitation assay and RNApol ChIP}

ChIP and RNApol ChIP procedures were performed according to Sandoval and colleagues [24], and Rodriguez and colleagues [25] with some modifications. AR42J cells were fixed by adding formaldehyde to a final concentration of $1 \%$ directly to the cell culture dish, and 
incubating for 7 minutes on a shaking platform, at room temperature. The cross linking reaction was stopped by adding glycine to a final concentration of $0.125 \mathrm{M}$, and cells were then washed twice with ice-cold PBS, scrapped and recovered by centrifugation at $3000 \times g$ for $5 \mathrm{~min}$. The pelleted cells were resuspended in $6 \mathrm{ml}$ of cell lysis buffer (HEPES 5mM, pH 8, $\mathrm{KCl} 85 \mathrm{mM}$, NP40 0.5\%) supplemented with protease inhibitor cocktail (Sigma), incubated on ice for $15 \mathrm{~min}$ and centrifuged at $1000 \times \mathrm{g}$ for $5 \mathrm{~min}$. The nuclei pellet was resuspended in $1 \mathrm{ml}$ of nuclei lysis buffer (Tris-HCl $50 \mathrm{mM}, \mathrm{pH}$ 8.1, EDTA $10 \mathrm{mM}$, SDS 1\%) and stored at $80{ }^{\circ} \mathrm{C}$ until use.

Cross-linked chromatin was sonicated on ice during 8 pulses of $10 \mathrm{~s}$ each, with a $37 \%$ amplitude on a Vibra-Cell VCX-500 sonicator (Sonics and Materials, Newtown, CT) to obtain chromatin fragments of $300-500 \mathrm{bp}$. This target size of chromatin fragments was confirmed by agarose gel electrophoresis. The sonicated chromatin was centrifuged at $14,000 \times g$ for $10 \mathrm{~min}$, and the supernatants were diluted 10 -fold with dilution buffer $(\mathrm{NaCl}$ $165 \mathrm{Mm}$, SDS 0.01\%, Triton X-100 1.1\%, EDTA $1.2 \mathrm{mM}$, Tris-HCl $16.7 \mathrm{mM}$, pH 8.0) supplemented with protease inhibitor cocktail (Sigma, St. Louis, MO). Aliquots from the diluted supernatants (equivalent to $50 \mu \mathrm{g}$ DNA) were taken and incubated for $2 \mathrm{~h}$ at $4^{\circ} \mathrm{C}$ with Dynabeads-protein G (Invitrogen, Carlsbad, CA) previously washed with PBS/BSA (5mg/ml) and saturated with tRNA from E. coli and $2 \mu \mathrm{g}$ of the corresponding antibody on a rotating platform (C/EBPß, P-CREB, P-ELK1, ATF2, EGR1, c-JUN, STAT3, NFאB (p65), ETS2, ATF3 and SRF for ChIP assay, or RNApol II for RNApol ChIP). The chromatin fragment/antibody/protein G-Dynabead immunocomplexes, were recovered applying a magnetic field, by placing the sample containing tubes in the appropriate magnet (Invitrogen, Carlsbad, CA). Immunocomplexes were washed twice with ice-cold low-salt buffer (HEPES $50 \mathrm{mM}, \mathrm{pH}$ 8.0, NaCl $140 \mathrm{mM}$, Triton X-100 1\%, Sodium Desoxycholate $0.1 \%$,EDTA $1 \mathrm{mM}$ ), twice with ice-cold high-salt buffer (HEPES $50 \mathrm{mM}, \mathrm{pH}$ 8.0, NaCl $500 \mathrm{mM}$, Triton X- 
100 1\%, Sodium Deoxycholate $0.1 \%$,EDTA $1 \mathrm{mM}$ ), twice with ice-cold LiCl buffer (Tris$\mathrm{HCl}$ 10mM, LiCl $250 \mathrm{mM}, \mathrm{NP}-40$ 0.5\%, Sodium Deoxycholate 0.5\%, EDTA 1mM) and finally once with TE buffer. During each washing step, the Dynabead suspensions were kept under rotation for 4 min at $4{ }^{\circ} \mathrm{C}$, and recovered with the magnet. After the elimination of any remaining TE buffer from the last wash, the immunoselected chromatin was eluted from the Dynabead-protein $\mathrm{G}$ in two consecutive steps, by adding $50 \mu \mathrm{l}$ of elution buffer (Tris- $\mathrm{HCl} 50$ $\mathrm{mM}$, EDTA $10 \mathrm{mM}$, SDS $1 \%$ ), vortexing and incubating for $10 \mathrm{~min}$ at $65^{\circ} \mathrm{C}$. The resulting $100 \mu \mathrm{l}$ fraction (IP fraction) was incubated at $65{ }^{\circ} \mathrm{C}$ overnight to reverse formaldehyde crosslinks, in the presence of proteinase $\mathrm{K}(0.4 \mathrm{mg} / \mathrm{ml})$. An aliquot of the cross-linked and diluted chromatin was treated in parallel as above, but in the absence of antibody (NoAb fraction) and the first supernatant, resulting from putting the sample on the magnet prior to the washing steps, was saved as the Input fraction. The DNA from all these samples (IP, NoAb and Input) was purified with a PCR purification kit (Qiagen, Valencia, CA) and used for PCR analysis of the target gen.

\section{PCR analysis of immunoprecipitated chromatin.}

Input, IP and (NoAb) fractions were analysed by PCR with the appropriate primer pairs to amplify products of 200 to $300 \mathrm{bp}$ in length, corresponding to either the promoter or the coding regions of the target gene. For the analysis, 1:500 dilutions of the Input and 1:30 of the IP and NoAb fractions were used. Primers were designed to amplify rat papl promoter and rat papl coding region. PCR fragments were size-fractionated by $2 \%$ agarose gel electrophoresis, stained with ethidium bromide and photographed with FLA3000 electronic autoradiography system (Fujifilm, Japan). Analysis of constitutive expressed $\beta$-actin gene was used as a positive control and analysis of an intergenic region was used as a negative control. Sequence primers are showed in Table 1.

\section{RNA isolation and RT-PCR}


Analysis of the expression of papl was conducted using a semiquantitative RT-PCR method. Total RNA from cells was extracted using the Trizol reagent (Invitrogen, Carlsbad, CA). One $\mu \mathrm{g}$ total RNA was used for amplification using the Promega AccessQuick RT-PCR System (Promega, Madison, WI) according to the manufacturer's instructions. The following primers were used: rat papl and rat gapdh as internal control for stable expression (housekeeping gene). Respective sequence primers are in Table 1. Fragments were amplified using 25-30 cycles of PCR, each cycle consisting of $15 \mathrm{~s}$ at $94^{\circ} \mathrm{C}, 30 \mathrm{~s}$ at $55^{\circ} \mathrm{C}$, and $1 \mathrm{~min}$ at $72^{\circ} \mathrm{C}$. The resulting RT-PCR products were electrophoresed on 2\% agarose gels with DNA markers, stained with ethidium bromide, and visualized under UV light.

\section{Real-time quantitative PCR}

Total RNA was isolated from AR42J cells exposed to PAP1 for $20 \mathrm{~min}$ and from non-treated control cells, using the Trizol reagent (Invitrogen, Carlsbad, CA). The RNA was quantified by measurement of the absorbance at 260 and $280 \mathrm{~nm}$ using a NanoDrop ND-1000 spectrophotometer (NanoDrop Technologies, USA). Reverse transcriptase real-time quantitative PCR was performed using an ABI Prism 7000 thermal cycler (Applied Biosystems, Foster City, CA). RT-PCR mixtures contained $0.5 \mu \mathrm{g}$ of total RNA and $200 \mathrm{nM}$ each of the forward and reverse primers. Primers were designed to amplify rat papl and rat gapdh as a housekeeping gene. Respective sequence primers are showed in Table 1. Reaction mixtures also contained HotStart Taq DNA polymerase, DNA double-stranded specific SYBR Green I dye, OmniScript and SensiScript reverse transcriptases, ROX passive dye, and nucleotides (Quantitect SYBR Green RT-PCR kit; Qiagen, Valencia, CA). Amplification was achieved following an initial incubation at $50{ }^{\circ} \mathrm{C}$ for $30 \mathrm{~min}$, followed by denaturation at 95 ${ }^{\circ} \mathrm{C}$ for $15 \mathrm{~min}$, and then 40 cycles of $94{ }^{\circ} \mathrm{C}$ for $15 \mathrm{~s}, 60{ }^{\circ} \mathrm{C}$ for $30 \mathrm{~s}$, and $72{ }^{\circ} \mathrm{C}$ for $30 \mathrm{~s}$. At the end of the 40 cycles, samples were subjected to melting analyses to confirm the specificity of PCR products. The fold induction of papl mRNA was determined by the $\Delta \mathrm{Ct}$ relative 
quantification method (Applied Biosystems, Foster City, CA). The amount of mRNA in each sample was normalized to the level of gapdh in cognate samples.

\section{Chloramphenicol Acetyltransferase gene reporter assay and cell transfection}

The rat papl gene promoter fragment including nucleotides -1253 to +10 was inserted upstream of the Chloramphenicol Acetyltransferase (CAT) gene in the pCAT-Basic vector (Promega, Madison, WI) as previously reported [26]. AR42J cells $\left(3 \times 10^{5}\right.$ per plate) were plated in 50-mm diameter culture plates 24 hours before transfection. For each plate, $1 \mu \mathrm{g}$ of the reporter vector (-1253 to +10-PAP1-CAT) and $1 \mu \mathrm{g}$ of $\mathrm{pCMV} / \beta$-gal were added to $6 \mu \mathrm{l}$ of FuGENE 6 according to the instructions of the supplier (Roche, Palo Alto, CA). The mixture was added to Dulbecco's modified Eagle's medium containing $3 \mathrm{ml}$ of $10 \%(\mathrm{w} / \mathrm{v})$ FCS. After 24 hours in culture, cells were treated with $500 \mathrm{ng}$ of PAP1 alone or in combination with SB203580 $(10 \mu \mathrm{M})$, PD98059 $(100 \mu \mathrm{M})$ or the JNK Inhibitor II $(100 \mu \mathrm{M})$ for an additional 24 hours-period. Cell extracts were prepared using the reporter lysis buffer (Promega, Madison, WI). CAT activity was determined using the phase-extraction procedure [27] and the $\beta$-galactosidase assay was performed essentially as described previously [26]. CAT activity was normalized to the $\beta$-galactosidase activity. CAT and $\beta$-galactosidase activities were always within linear range of the assay.

\section{SDS-PAGE and Western blot}

Cells were lysed using the Nuclear Extract Kit (Active Motif, Carlsbad, CA) under conditions for preparation of cytoplasmatic and nuclear extracts. SDS-PAGE was performed on $10 \%$ acrylamide gels. Proteins were electrotransferred to nitrocellulose membranes and probed with primary antibody (anti-P-p38 1/1000, anti-P-p44/42 1/1000, anti-P-JNK 1/1000; Anti- $\beta$ actin 1/1000). The membranes were incubated with the corresponding peroxidase-conjugated secondary Ab, washed, and then incubated with ECL reagents from Bio-Rad (Hercules, CA) 
before exposure to high performance chemiluminescence films. Gels were calibrated using Bio-Rad standard proteins (Hercules, CA) with markers covering a 7-240 kDa range.

\section{Bioinformatic analysis of pap1 promoter region}

papl promoter sequence (1000 bp) was analysed using the transcription factor binding sites (TFBS) analysis tool MatInspector (http://www.genomatix.de/) [28].

\section{Statistical analysis}

Data were expressed as mean \pm SEM. Means of values from different groups were compared using a one-way analysis of variance. Tukey's multiple comparison test was performed for evaluation the significance of differences between groups. Differences were assumed to be significant when $\mathrm{p}<0.05$.

\section{Densitometric analysis}

ImageJ 1.32 software (obtained from the http://rsbweb.nih.gov/ij/download.html) was used to quantify the intensities of the bands obtained in PCR experiments. 


\section{Results}

\section{Induction of pap1 gene expression in response to PAP1}

We confirmed our previous results showing the positive feedback induction of PAP1 in AR42J pancreatic acinar cells. AR42J cells displayed a time-dependent induction of pap1 gene expression after adding PAP1 to the culture media. Kinetic analysis of the induction revealed that the levels of papl mRNA increased $30 \mathrm{~min}$ after addition of PAP1 at 500ng/ml (Figure 1A). This dose has been previously reported to be effective in inducing PAP1 itself [23]. Specificity of PAP1 induced response was verified by incubating the protein with $1 \mu \mathrm{M}$ of rabbit anti-PAP1 neutralizing antibody [20] for 30 minutes. Then, AR42J cells were stimulated with this mixture for 40 minutes. Figure $1 \mathrm{~B}$ shows the effective neutralizing ability of anti-PAP1 antibody on PAP1 induction. These results allowed us to use the papl gene promoter as a strategy to study the signaling pathways activated by PAP1 using ChIP and RNApol ChIP assays.

\section{Identification of transcription factors bound to the pap1 gene promoter in vivo}

To verify the binding of regulatory factors to the papl promoter in response to PAP1, we carried out a ChIP assay in growing AR42J cells. After cross-linking and immunoprecipitation, enrichment of the human papl promoter was monitored by PCR amplification using specific primers for the promoter region. In order to verify the results obtained, the same samples employed for the ChIP assay were used for the RNA polymerase ChIP assay, as previously described. The $\alpha$-RNA polymerase antibody precipitated both promoter and coding chromatin fragments, thus confirming that the papl gene is expressed in AR42J cells. An augmented transcription was observed 20 min after PAP1 addition to the cell culture medium (Figure. 2). In that basis, we established an incubation time of 20 min to test the binding of nuclear regulatory factors to the papl promoter region. In vivo binding of factors to papl promoter was monitored using antibodies against C/EBP $\beta$, P-CREB, P-ELK1, 
ATF2, EGR1, c-JUN, STAT3, NFkB (p65), ETS2, ATF3 and SRF. Figure 3 depicts the presence of downstream targets of PAP1. EGR1 and STAT3 bound to the promoter region of papl gene in cells without PAP1 treatment. After stimulation with PAP1, the binding of C/EBP $\beta$, P-CREB, P-ELK1, EGR1, STAT3 and ETS2 was dramatically increased, while that of ATF2, c-JUN, NFkB (p65), ATF3 and SRF remained unchanged.

\section{PAP1 signal transduction involved MAPK signaling pathway}

Next, we investigated whether PAP1 directly affect MAPK signaling. We used Western blot and specific antibodies against the active (phosphorylated) forms of the kinases. As summarized in Figure 4, AR42J cells presented basal levels of phosphorylation of the three members of the MAPK superfamily: p44/42, p38 and JNK. However, 30 min after PAP1 treatment, an augmented activation of the p44/42, p38 and JNK protein kinases was observed, suggesting that PAP1 signal transduction involves the MAPK superfamily.

\section{Effect of MAPKs specific inhibitors on PAP1-mediated induction of pap1 mRNAGiven}

the fact that PAP1 enhanced the phosphorylation of MAPK family members, we examined the effect of MAPK specific inhibitors on PAP1-mediated induction of pap1 mRNA. Pancreatic acinar cells were treated for $20 \mathrm{~min}$ with vehicle, PAP1 $(500 \mathrm{ng} / \mathrm{ml})$ or pre-treated with different MAPK specific inhibitors: SB203580 (p38 MAPK inhibitor; 100 $\mu \mathrm{M}$ ), PD98059 (p44/42 inhibitor; $100 \mu \mathrm{M})$, and JNK Inhibitor II (100 $\mu \mathrm{M})$ for $30 \mathrm{~min}$ and then stimulated with PAP1. As shown in Figure 5, the pharmacological inhibition of the three main MAPK family members markedly inhibited the activation of pap1 mRNA, thus indicating that activation of the MAPK superfamily is essential for pap1 mRNA synthesis in response to PAP1. In order to verify the effect of MAPK inhibition on the activation of the pap1 promoter, an additional experiment was carried out using a gene reporter assay. Figure 6 shows that all inhibitors resulted in a blockage of the CAT activity induced by PAP1. 


\section{Discussion}

A plethora of functional roles have been attributed to the stress-induced secretory protein PAP1. This protein has been reported to be mitogenic, anti-apoptotic or anti-inflammatory, to regulate cellular adhesion, promote bacterial aggregation or increase resistance to anti-tumoral agents, the nature of these functions depending on the cell type used as model and the environment.

Since different investigators have attributed diverse physiological roles to PAP1, little is known about the downstream signaling pathways activated by PAP1. To date, it was shown that in cultured motor neurons, PAP1 signals for survival through the phosphoinositol-3kinase (PI3 kinase)/AKT kinase pathway [12]. In hepatocytes, PAP1 stimulates PKAdependent phosphorylation of the pro-apoptotic Bad protein, suggesting that PAP1 may compete with cAMP to stimulate PKA activity [15]. Moreover, recent data have shown an antiinflammatory role for PAP1 through the inhibition of NFKB signaling induced by TNF $\alpha$ in pancreatic acinar cells [23]. This inhibition takes place as a result of JAK/STAT3 activation suggesting the existence of a crosstalk between both signaling pathways.

Despite this well documented data, it can barely account for all PAP1 functions. In an effort to complete the picture, we used a pancreatic acinar cell line AR42J known to respond to PAP1. In a previous work on this cell line, we used immunopurified PAP1 from rat pancreatic juice to describe a positive feedback mechanism of PAP1. Here we show the same results using human PAP1 produced in Pichia Pastoris, which is not a surprise given the important sequence similarities between the two homologs. Analysis of the kinetics of PAP1 induction revealed that pap1 mRNA expression analyzed by RT-PCR in response to PAP1 itself was time-dependent (Figure 1A) and already increased 30 min after the treatment. The specificity of PAP1 induced response was verified using a neutralizing anti-PAP1 antibody (Figure 1B). These results allowed us to use the ChIP assay on the papl gene promoter to study the 
signaling pathways activated by PAP1. We, therefore, tested by RNApol ChIP assay the recruitment of the RNA $\alpha$-polymerase to papl promoter. As shown in Figure 2, an enhanced binding of the RNApol II transcriptional complex is observed 20 min after PAP1 addition to the cell culture medium.

Several potential transcription factor binding sites are present on the papl promoter. Analysis of the $1 \mathrm{~kb}$ promoter sequence revealed potential binding sites of some important transcription factors, including C/EBP, P-CREB, ATF2, STAT3, ETS2 and SRF. In addition to these, we also evaluated the binding of the nuclear factors P-ELK1, EGR1, c-JUN, NFאB and ATF3 to study their effects on pap1 promoter occupation. As shown on Figure 3, EGR1 and STAT3 are bound to papl promoter in the absence of PAP1 treatment indicating that papl may be considered as a "potentially active" gene prepared to respond promptly to an appropriated cellular stimulus. After stimulation with PAP1, we could obtain significant amplification of the papl promoter region from DNA co-immunoprecipitated using the $\mathrm{C} / \mathrm{EBP} \beta, \mathrm{P}-\mathrm{CREB}, \mathrm{P}-$ ELK1, EGR1, STAT3 and ETS2 antibodies, indicating that in these conditions, these transcription factors are bound to the binding site of papl promoter gene in the cells. In a previous study, we already reported the PAP1 positive feedback through a JAK/STAT3 mechanism [23]. Therefore, the binding of STAT3 to the PAP1 promoter would be consistent with the STAT3-dependent role of PAP1.

Regarding NFkB, we did not find this nuclear factor bound to the PAP1 promoter. This result is in keeping with previous studies showing no activation of $\mathrm{NF \kappa B}$ in pancreatic acinar cells or macrophages in response to PAP1 [23, 2]. However, different results have been found with other PAP isoforms. Using a rat macrophage cell line, Viterbo et al. reported that PAP2, the most expressed PAP isoform during acute pancreatitis, up-regulated the expression of proinflammatory cytokines IL1, IL6 and TNF $\alpha$ [29]. These differences seem to be related with 
the different functional properties shown by the different members of the PAP superfamily $[10]$.

The activation of nuclear factors C/EBP $\beta$, P-CREB, P-ELK1, EGR1 and ETS2 observed in response to PAP1 served as a specific readout for MAPK superfamily activation. Nevertheless, other signaling cascades such as the PI3 kinase/AKT and $\mathrm{Ca}^{2+}$-specific signals activated by growth factors or cellular stress are known to converge on some of these factors, controlling their activity.

Then, we further delineated the possible influence of PAP1 on the activation of MAPK signaling pathway. A wide variety of extracellular stimuli induce sequential phosphorylation and activation of the MAPK pathway. This superfamily of proteins consists of three main protein kinase families: the extracellular signal-regulated protein kinases (ERK or p44/42), the c-Jun N-terminal kinases (JNK) and the p38 family of kinases. Each molecule is activated by distinct pathways and transmits signals either independently or in coordination [30, 31]. The MAPK pathway is involved in diverse cellular functions including cell proliferation, cell differentiation and apoptosis as well as inflammation. Thus, it is conceivable that PAP1 triggers the MAPK signaling pathway. In this line, Lieu et al. reported changes in p44/42 activation in PAP1 knockout mice during liver regeneration, suggesting that this MAPK could be involved in the regenerative effects of PAP1 [32].

Western Blot analysis of MAPK indicated that AR42J cells presented with a basal level of phosphorylation of p44/42, p38 and JNK (Figure 4). However, PAP1 treatment enhanced the phosphorylation of all three MAPKs, suggesting that some of the effects of PAP1 could be mediated by activation of MAPK signaling and thus downstream transcription events. This possibility was evaluated by using specific inhibitors of these three major families of MAPKs and measuring the induction of papl mRNA as well as the activation of papl gene promoter in a gene reporter assay. Results indicated that the addition of p44/42, p38 and JNK 
pharmacological inhibitors completely blocked the activation of papl promoter as well as the induction of papl mRNA in response to PAP1 (Figures 5 and 6). It was therefore concluded that these signaling events are necessary to papl gene regulation.

Most experimental evidences obtained so far demonstrate that MAPK signaling cascades are involved in the pathogenesis of acute pancreatitis [33]. An early activation of all three MAPK in the pancreas within minutes was indeed observed in experiments involving various models of experimental acute pancreatitis [34-36]. This is of interest given the fact that our results indicate that PAP1 induces itself in a positive feedback mechanism mediated by MAPKs activation. In these conditions, it is not surprising to find high amounts of this protein during this acute inflammatory disease.

Finally, some reports indicate that MAPK cascades can also influence other signaling pathways. It is known that p44/42 participate in STAT3 serine 727 phosphorylation in vivo in growth factor-stimulated cells and in vitro as well [37] suggesting a possible dynamic interplay between both MAPK and JAK/STAT3 pathway upon activation by PAP1.

In summary, the present study demonstrates that part of the physiological effects of PAP1, including its self-induction, is strongly dependent on the activation of MAPK signaling pathway (figure 7). These results make a contribution to the in-depth knowledge of the mechanisms involved in PAP1 physiological functions. 


\section{Acknowledgements}

This work was supported by the FIS PI050599 and FIS PI081608 projects to E. Folch-Puy, Acción Integrada HF2006-0092 and CIBERehd to D. Closa and Spanish Ministry of Science and Technology BFU2007-63120 and CSD2006-49 to G. López-Rodas. CIBERehd is funded by the Instituto de Salud Carlos III. E. Folch-Puy is the recipient of a Ramón y Cajal contract from the Spanish Ministry of Education and Science. M. Ferrés-Masó is the recipient of a FIS-Instituto de Salud Carlos III contract PI050599. 


\section{References}

1. Keim, V., Rohr, G., Stockert, H.G. and Haberich, F.J. (1984) An additional secretory protein in the rat pancreas. Digestion 29, 242-249.

2. Gironella, M., Iovanna, J.L., Sans, M., Gil, F., Peñalva, M., Closa, D., Miquel, R., Piqué, J.M. and Panés, J. (2005) Anti-inflammatory effects of pancreatitis associated protein in inflammatory bowel disease. Gut 54, 1244-1253.

3. Duplan, L., Michel, B., Boucraut, J., Barthellémy, S., Desplat-Jego, S., Marin, V., Gambarelli, D., Bernard, D., Berthézène, P., Alescio-Lautier, B. and Verdier, J.M. (2001) Lithostathine and pancreatitis-associated protein are involved in the very early stages of Alzheimer's disease Neurobiol. Aging 22, 79-88.

4. Christa, L., Simon, M.T., Brezault-Bonnet, C., Bonte, E., Carnot, F., Zylberberg, H., Franco, D., Capron, F., Roskams, T. and Bréchot, C. (1999) Hepatocarcinoma-intestinepancreas/pancreatic associated protein (HIP/PAP) is expressed and secreted by proliferating ductules as well as by hepatocarcinoma and cholangiocarcinoma cells. Am. J. Pathol. 155, 1525-1533.

5. Xie, M.J., Motoo, Y., Iovanna, J.L., Su, SB., Ohtsubo, K., Matsubara, F. and Sawabu, N. (2003) Overexpression of pancreatitis-associated protein (PAP) in human pancreatic ductal adenocarcinoma. Dig. Dis. Sci. 48, 459-464.

6. Motoo, Y., Itoh, T., Su, S.B., Nakatani, M.T., Watanabe, H., Okai, T. and Sawabu, N. (1999) Serum levels of pancreatitis-associated protein in digestive diseases with special reference to gastrointestinal cancers. Dig. Dis. Sci. 44, 1142-1147.

7. Demaugre, F., Philippe, Y., Sar, S., Pileire, B., Christa, L., Lasserre, C. and Brechot, C. (2004) HIP/PAP, a C-type lectin overexpressed in hepatocellular carcinoma, binds the RII alpha regulatory subunit of cAMP-dependent protein kinase and alters the cAMP-dependent protein kinase signalling. Eur. J. Biochem. 271, 3812-3820. 
8. Dusetti, N.J., Mallo, G.V., Ortiz, E.M., Keim, V., Dagorn, J.C. and Iovanna, J.L. (1996) Induction of lithostathine/reg mRNA expression by serum from rats with acute pancreatitis and cytokines in pancreatic acinar AR-42J cells. Arch. Biochem. Biophys. 330, 129-132.

9. Bimmler, D., Schiesser, M., Perren, A., Scheele, G., Angst, E., Meili, S., Ammann, R. and Graf, R. (2004) Coordinate regulation of PSP/reg and PAP isoforms as a family of secretory stress proteins in an animal model of chronic pancreatitis. J. Surg. Res. 15, 122-135.

10. Graf, R., Schiesser, M., Lüssi, A., Went, P., Scheele, G.A. and Bimmler, D. (2002) Coordinate regulation of secretory stress proteins (PSP/reg, PAP I, PAP II, and PAP III) in the rat exocrine pancreas during experimental acute pancreatitis. J. Surg. Res. 2002 105, 136-144. 11. Bartoli, C., Baeza, N., Figarella, C., Pellegrini, I. and Figarella-Branger, D. (1998) Expression of peptide-23/pancreatitis-associated protein and Reg genes in human pituitary and adenomas: comparison with other fetal and adult human tissues. J. Clin. Endocrinol. Metab. 83, 4041-4046.

12. Nishimune, H., Vasseur, S., Wiese, S., Birling, M.C., Holtmann, B., Sendtner, M., Iovanna, J.L. and Henderson, C.E. (2000) Reg-2 is a motoneuron neurotrophic factor and a signaling intermediate in the CNTF survival pathway. Nat. Cell Biol. 2, 906-914.

13. Ortiz, E.M., Dusetti, N.J., Vasseur, S., Malka, D., Bödeker, H., Dagorn, J.C. and Iovanna, J.L. (1998) The pancreatitis-associated protein is induced by free radicals in AR42J cells and confers cell resistance to apoptosis. Gastroenterology 114, 808-816.

14. Malka, D., Vasseur, S., Bödeker, H., Ortiz, E.M., Dusetti, N.J., Verrando, P., Dagorn, J.C. and Iovanna, J.L. (2000) Tumor necrosis factor alpha triggers antiapoptotic mechanisms in rat pancreatic cells through pancreatitis-associated protein I activation. Gastroenterology 119, 816-828.

15. Simon, M.T., Pauloin, A., Normand, G., Lieu, H.T., Mouly, H., Pivert, G., Carnot, F., Tralhao, J.G., Brechot, C. and Christa, L. (2003) HIP/PAP stimulates liver regeneration after 
partial hepatectomy and combines mitogenic and anti-apoptotic functions through the PKA signaling pathway. FASEB J. 17, 1441-1450.

16. Livesey, F.J., O’Brien, J.A., Li, M., Smith, A.G., Murphy, L.J. and Hunt, S.P. (1997) A Schwann cell mitogen accompanying regeneration of motor neurons. Nature 390, 614-618.

17. Moucadel, V., Soubeyran, P., Vasseur, S., Dusetti, N.J., Dagorn, J.C. and Iovanna, J.L. (2001) Cdx1 promotes cellular growth of epithelial intestinal cells through induction of the secretory protein PAP I. Eur. J. Cell Biol. 80, 156-163.

18. Christa, L., Carnot, F., Simon, M.T., Levavasseur, F., Stinnakre, M.G., Lasserre, C., Thepot, D., Clement, B., Devinoy, E. and Brechot, C. (1996) HIP/PAP is an adhesive protein expressed in hepatocarcinoma, normal Paneth, and pancreatic cells. Am. J. Physiol. 271, G993-G1002.

19. Valery, C., Vasseur, S., Sabatier, F., Iovanna, J.L., Dagorn, J.C., Grob, J.J. and Verrando, P. (2001) Pancreatitis associated protein I (PAP-I) alters adhesion and motility of human melanocytes and melanoma cells. J. Invest. Dermatol. 116, 426-433.

20. Vasseur, S., Folch-Puy, E., Hlouschek, V., Garcia, S., Fiedler, F., Lerch, M.M., Dagorn, J.C., Closa, D. and Iovanna, J.L. (2004) p8 improves pancreatic response to acute pancreatitis by enhancing the expression of the anti-inflammatory protein pancreatitis-associated protein I. J. Biol. Chem. 279, 7199-7207.

21. Zhang, H., Kandil, E., Lin, Y.Y., Levi, G. and Zenilman, M.E. (2004) Targeted inhibition of gene expression of pancreatitis-associated proteins exacerbates the severity of acute pancreatitis in rats. Scand. J. Gastroenterol. 39, 870-881.

22. Gironella, M., Folch-Puy, E., LeGoffic, A., Garcia, S., Christa, L., Smith, A., Tebar, L., Hunt, S.P., Bayne, R., Smith, A.J., Dagorn, J.C., Closa, D. and Iovanna JL. (2007) Experimental acute pancreatitis in PAP/HIP knock-out mice. Gut 56, 1091-1097. 
23. Folch-Puy, E., Granell, S., Dagorn, J.C., Iovanna, J.L. and Closa D. (2006) Pancreatitisassociated protein I suppresses NF-kappa B activation through a JAK/STAT-mediated mechanism in epithelial cells. J. Immunol. 176, 3774-3779.

24. Sandoval, J., Rodríguez, J.L., Tur, G., Serviddio, G., Pereda, J., Boukaba, A., Sastre, J., Torres, L., Franco, L. and López-Rodas, G. (2004) RNAPol-ChIP: a novel application of chromatin immunoprecipitation to the analysis of real-time gene transcription. Nucleic Acids Res. 32, e88.

25. Rodríguez, J.L., Sandoval, J., Serviddio, G., Sastre, J., Morante, M., Perrelli, M.G., Martínez-Chantar, M.L., Viña, J., Viña, J.R., Mato, J.M., Avila, M.A., Franco, L. and LópezRodas G. (2006) Id2 leaves the chromatin of the E2F4-p130-controlled c-myc promoter during hepatocyte priming for liver regeneration. Biochem. J. 398, 431-437.

26. Dusetti, N.J., Ortiz, E.M., Mallo, G.V., Dagorn, J.C. and Iovanna, J.L. (1995) Pancreatitisassociated protein I (PAP I), an acute phase protein induced by cytokines. Identification of two functional interleukin-6 response elements in the rat PAP I promoter region. J. Biol. Chem. 270, 22417-22421.

27. Seed, B. and Sheen, J.Y. (1988) A simple phase-extraction assay for chloramphenicol acyltransferase activity. Gene 67, 271-277.

28. Cartharius, K., Frech, K., Grote, K., Klocke, B., Haltmeier, M., Klingenhoff, A., Frisch, M., Bayerlein, M. and Werner, T. (2005) MatInspector and beyond: promoter analysis based on transcription factor binding sites. Bioinformatics 21,2933-2942.

29. Viterbo, D., Bluth, M.H., Lin, Y.Y., Mueller, C.M., Wadgaonkar, R. and Zenilman, M.E. (2008) Pancreatitis-associated protein 2 modulates inflammatory responses in macrophages. J. Immunol. 181, 1948-1958.

30. Krishna, M. and Narang, H. (2008) The complexity of mitogen-activated protein kinases (MAPKs) made simple. Cell. Mol. Life Sci. 65, 3525-3244. 
31. Kondoh, K., Torii, S. and Nishida, E. (2005) Control of MAP kinase signaling to the nucleus. Chromosoma 114, 86-91.

32. Lieu, H.T., Simon, M.T., Nguyen-Khoa, T., Kebede, M., Cortes, A., Tebar, L., Smith, A.J., Bayne, R., Hunt, S.P., Bréchot, C. and Christa, L. (2006) Reg2 inactivation increases sensitivity to Fas hepatotoxicity and delays liver regeneration post-hepatectomy in mice. Hepatology 44, 1452-1464.

33. Pereda, J., Sabater, L., Cassinello, N., Gómez-Cambronero, L., Closa, D., Folch-Puy, E., Aparisi, L., Calvete, J., Cerdá, M., Lledó, S., Viña, J. and Sastre, J. (2004) Effect of simultaneous inhibition of TNF-alpha production and xanthine oxidase in experimental acute pancreatitis: the role of mitogen activated protein kinases. Ann. Surg. 240, 108-116.

34. Dabrowski, A., Grady, T., Logsdon, C.D. and Williams, J.A. (1996) Jun kinases are rapidly activated by cholecystokinin in rat pancreas both in vitro and in vivo. J. Biol. Chem. 271, 56865690.

35. Schafer, C., Ross, S.E., Bragado,. MJ., Groblewski, G.E., Ernst, S.A. and Williams, J.A. (1998) A role for the p38 mitogen-activated protein kinase/Hsp 27 pathway in cholecystokinininduced in the actin cytoskeleton in rat pancreatic acini. J. Biol. Chem. 273, 24173-24180.

36. Wagner, A.C., Metzler, W., Hofken, T., Weber, H. and Göke, B. (1999) p38 map kinase is expressed in the pancreas and is immediately activated following cerulein hyperstimulation. Digestion 60, 41-47.

37. Chung, J., Uchida, E., Grammer, T.C. and Blenis, J. (1997) STAT3 serine phosphorylation by ERK-dependent and -independent pathways negatively modulates its tyrosine phosphorylation. Mol. Cell. Biol. 17, 6508-6516. 
Table 1: Primers used for RT-PCR and real time PCR

\begin{tabular}{|c|c|}
\hline Name & Primer \\
\hline \multirow[t]{2}{*}{ rat papl (promoter) } & Forward: 5'-ATGCCACCATTTTTTCCTTGTG-3' \\
\hline & Reverse: 5'-GAT GGGAAGCACTTGGCATT-3' \\
\hline \multirow[t]{2}{*}{ rat papl (coding region) } & Forward: 5'-CAAAGGCTCCC AGGCATATG-3' \\
\hline & Reverse: 5'- GGCCAGCTATGTGAGGAACAA-3' \\
\hline \multirow[t]{2}{*}{ rat papl (real time) } & Forward: 5'-ACTCCATGACCCCACTCTTG -3' \\
\hline & Reverse: 5'-TGACAAGCTGCCACAGAATC -3' \\
\hline \multirow[t]{2}{*}{ rat $\beta$-actin (coding region) } & Forward: 5'-AGAGCAAGAGAGGCATCCTG-3' \\
\hline & Reverse: 5'-GGGTCATCTTTTCACGGTTGG-3' \\
\hline \multirow[t]{2}{*}{ rat gapdh (real time) } & Forward: 5'-GTGTGTCTTTCCGCTGTTTTC -3' \\
\hline & Reverse: 5'-TGTGCTGTGCTTATGGTCTCA 3' \\
\hline \multirow[t]{2}{*}{ rat papl (RT-PCR) } & Forward: 5'-TGACAAGCTGCCACAGAATC-3' \\
\hline & Reverse: 5'-GCTCCTACTGCTATGCCCTG-3' \\
\hline \multirow[t]{2}{*}{ rat gapdh (RT-PCR) } & Forward: 5'-ATGGGAAGCTGGTCATCAAC-3' \\
\hline & Reverse: 5'-CCACAGTCTTCTGAGTGGCA-3' \\
\hline \multirow[t]{2}{*}{ rat intergenic } & Forward: 5'-TGCCGGTTATCACTCTCTCATGC-3' \\
\hline & Reverse: 5'-GGTCTTGGTTCAGTCTTCACATGC-3' \\
\hline
\end{tabular}




\section{Figure legends}

Figure 1. Time course of pap1 mRNA expression in response to PAP1. AR42J cells were stimulated with 500ng PAP1/mL culture medium at different time-points (A) or with a mixture of PAP1 plus a blocking anti-PAP1 antibody for $40 \mathrm{~min}$ (B). Total RNA was extracted and subjected to RT-PCR using specific primers for papl and gapdh (internal control). Products were analyzed by $2 \%$ agarose ethidium bromide gel. Results are shown for one of three representative experiments.

Figure 2. RNApol ChIP analysis of the rat pap1 transcription at different times of PAP1 treatment. The cross-linked chromatin samples were immunoprecipitated with an anti-RNA polymerase II antibody and the immunoprecipitate were analyzed by PCR using primers specific for the papl coding region. For each time-point, a sample of total chromatin (Input) was included in the PCR. The presence of RNA polymerase in these regions is taken as a measure of actual transcription. Constitutive expressed $\beta$-actin gene was used as a positive control and an intergenic region was used as a negative control. No Ab, no antibody.

Figure 3. ChIP analysis of pap1 promoter occupation during PAP1-treated AR42J cells. ChIP analysis was performed to monitor the binding of nuclear factors within the PAP1 promoter. In vivo binding of factors to papl gene 20 min after PAP1 treatment was monitored using antibodies against C/EBP $\beta$, P-CREB, P-ELK1, ATF2, EGR1, c-JUN, STAT3, NFאB (p65), ETS2, ATF3 and SRF. The immunoprecipitated samples were analyzed by PCR using primers of the papl promoter region. The normalized integrated density of the immunoprecipitated samples bands was included as a quantification of the relative intensity of the transcriptional binding. Results are shown for one of three representative experiments.

Figure 4. Effect of PAP1 on MAPKs activity. Phosphorylation levels in response to PAP1 of the three main members of the MAPK superfamily were assessed by Western blot. AR42J cells were stimulated with or without $500 \mathrm{ng} / \mathrm{ml}$ PAP1 for $30 \mathrm{~min}$ and cell lysates were 
subjected to immunoblotting using anti-P-p44/42 (A), anti-P-p38 (B) and anti-P-JNK (C) antibodies. The presence of PAP1 enhanced the expression of phosphorylated, active forms of the three MAPKs. The same membranes were re-blotted for anti- $\beta$-actin to check loads were similar. Immunoblots shown are representative for one of three independent experiments.

Figure 5. Effect of MAPK specific inhibitors on PAP1-mediated induction of pap1 mRNA. AR42J cells were treated for $20 \mathrm{~min}$ with vehicle, PAP1 (500 ng/ml) or pre-treated with different MAPK specific inhibitors: p44/42 inhibitor (SB203580; $100 \mu \mathrm{M})$, p38 inhibitor (PD98059; $100 \mu \mathrm{M}$ ), and JNK inhibitor (JNK Inhibitor II; $100 \mu \mathrm{M}$ ) for $30 \mathrm{~min}$ before stimulation with PAP1. papl mRNA induction levels were quantified by real-time PCR and normalized to gapdh mRNA expression. p38, p44/42 and JNK MAPKs inhibitors decreased papl mRNA induction. Results are expressed as mean values \pm S.E.M. ${ }^{*} \mathrm{p}<0.05$ vs $\mathrm{C},{ }^{+} \mathrm{p}<0.05$ vs P. C, control. P, PAP1. Results are shown for one of three representative experiments.

Figure 6. Transcription activation of the pap1 promoter by PAP1 is inhibited by MAPK inhibitors SB203580, PD98059 and the JNK Inhibitor II. AR42J cells were transiently transfected with the -1253 to +10-PAP1-CAT construct together with $\mathrm{pCMV} / \beta$-gal vector used as an internal control for the transfections. After transfection, the cells were incubated for $24 \mathrm{~h}$ and then incubated with $500 \mathrm{ng}$ of PAP1 alone or in combination with p44/42 inhibitor (SB203580; $100 \mu \mathrm{M}$ ), p38 inhibitor (PD98059; $100 \mu \mathrm{M}$ ), and JNK inhibitor (JNK Inhibitor II; $100 \mu \mathrm{M}$ ) by an additional 24 hours-period. Cells were then harvested, lysed and assayed for both CAT and $\beta$-galactosidase activities. Results are expressed as mean values \pm S.E.M. ${ }^{*} \mathrm{p}<0.05$ vs $\mathrm{C},{ }^{+} \mathrm{p}<0.05$ vs P. C, control. P, PAP1. Results are shown for one of three independent experiments.

Figure 7. Schematic diagram of MAPKs signal transduction pathway induced by PAP1. In AR42J cells, we provide evidence for activation of three MAPKs by PAP1: p38, p44/42 and JNK MAPKs are induced as consequence of the interaction of PAP1 with its receptor and 
subsequently phosphorylated. Several nuclear factors related to the MAPK family eventually bind the promoter region of PAP1. 
A

\begin{tabular}{l|llllllll} 
& 0 & 5 & 10 & 15 & 20 & 30 & 40 & min \\
gap1 & & & & & & & &
\end{tabular}

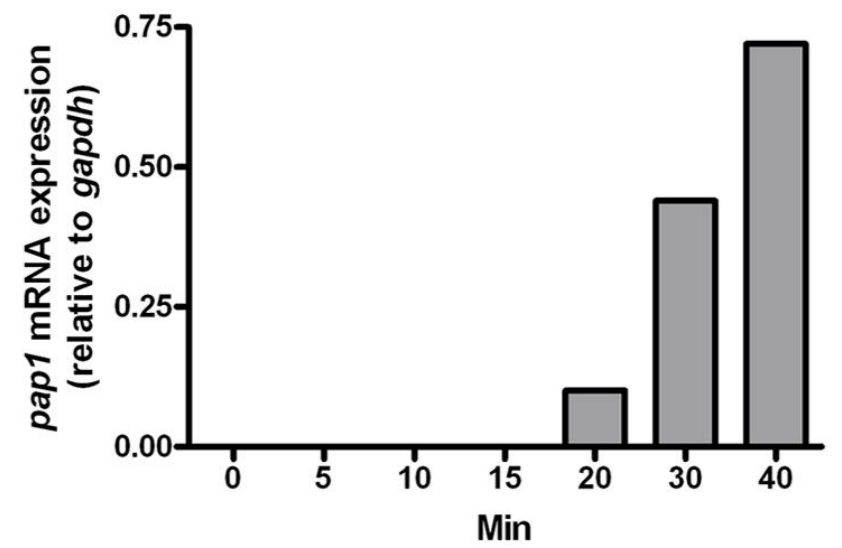

B

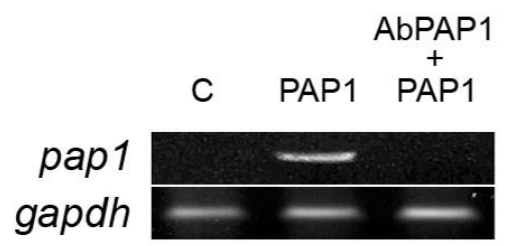

Figure 1 


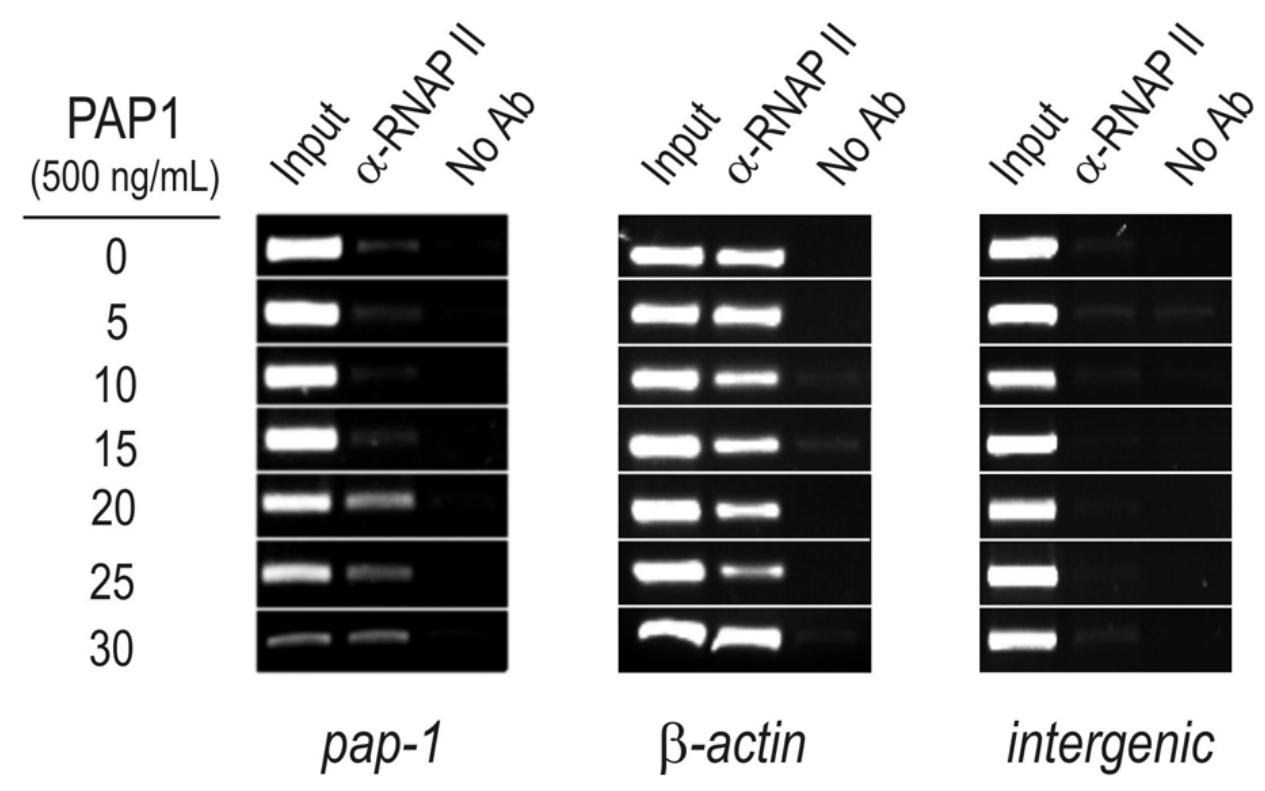

Figure 2 

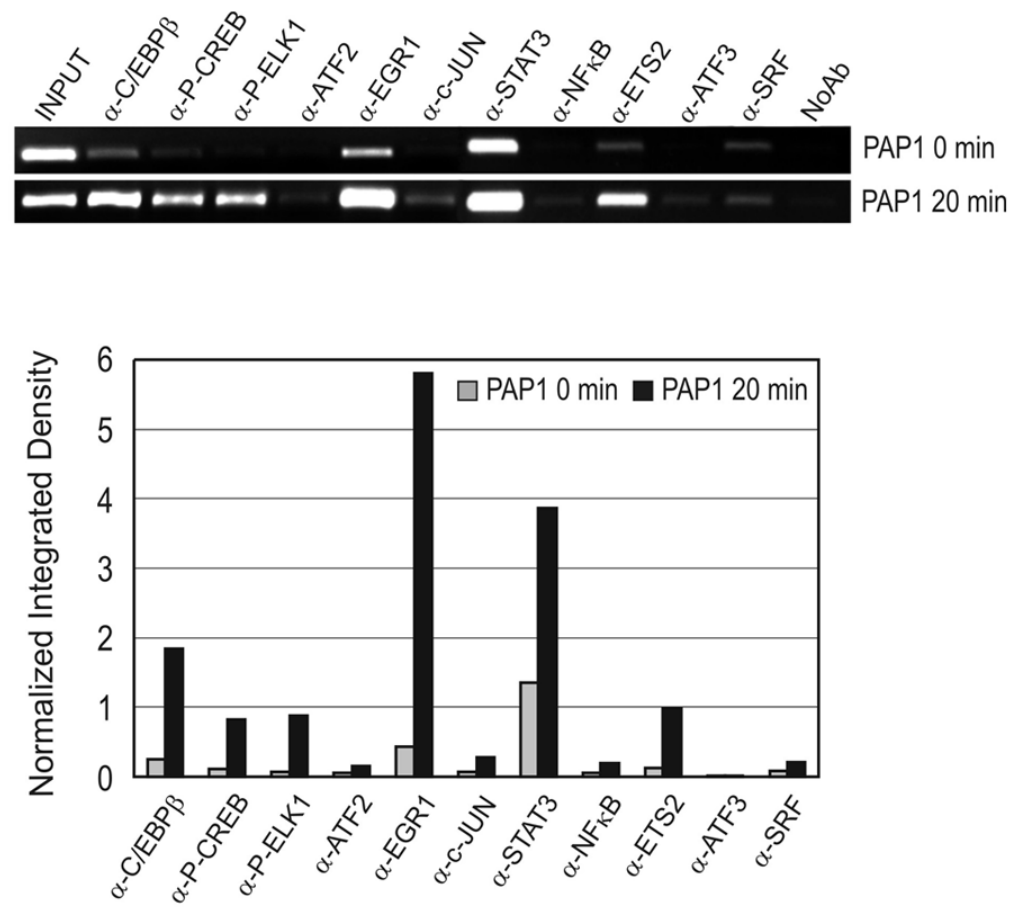

Figure 3 


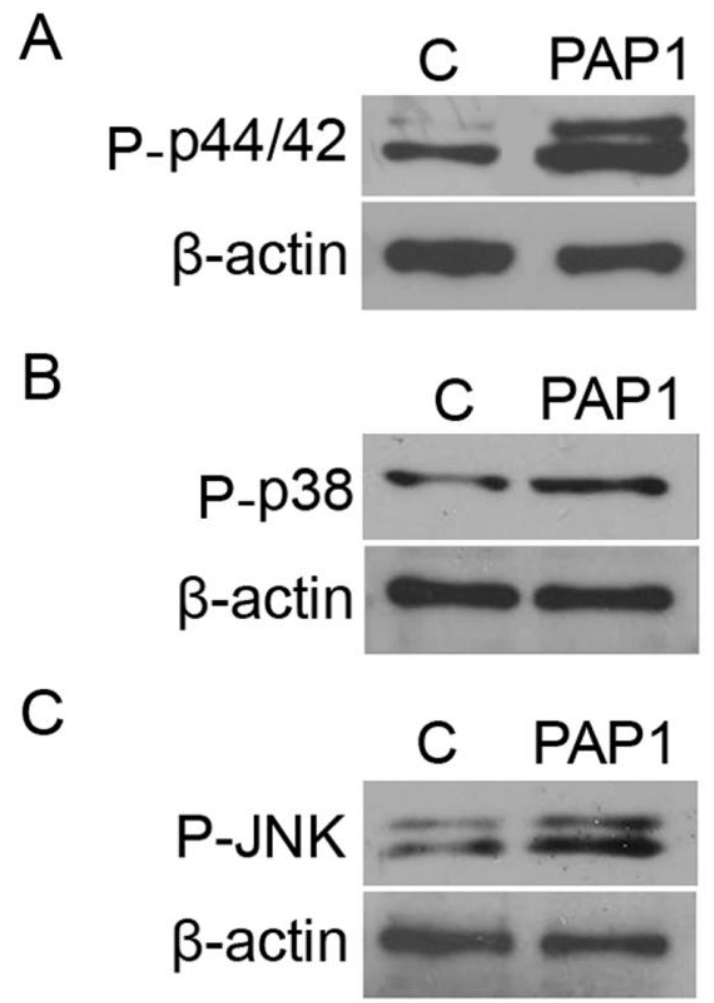

Figure 4 


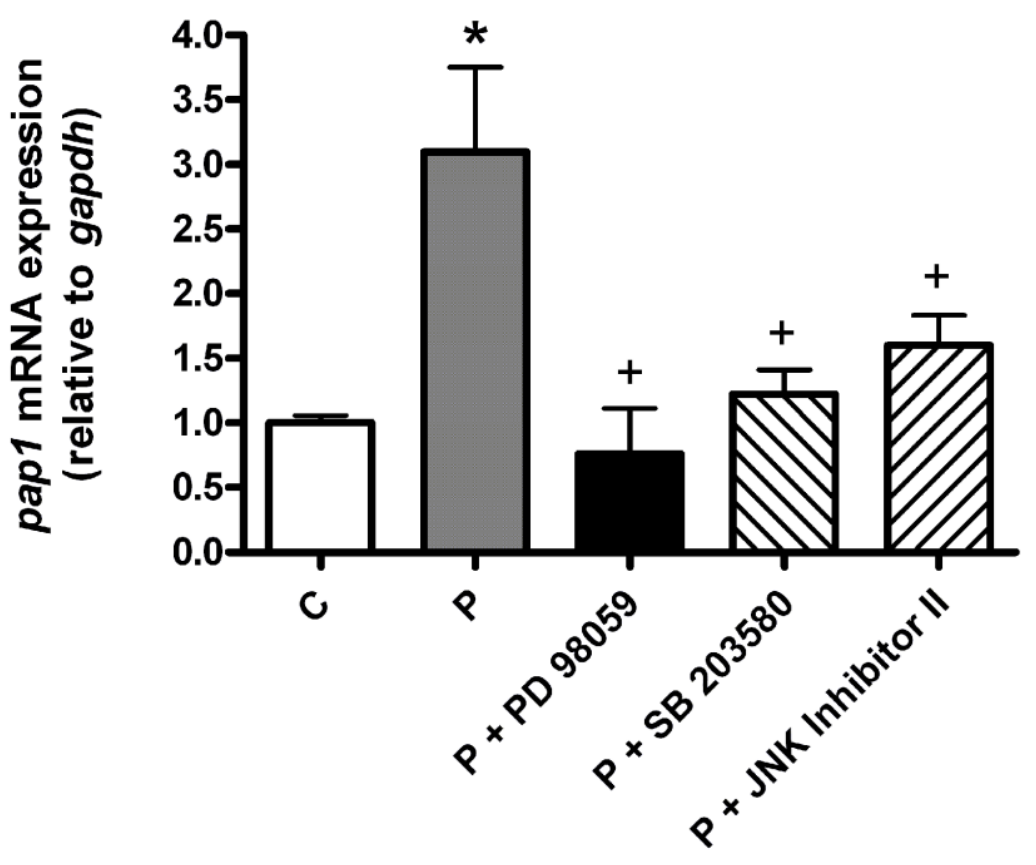

Figure 5 


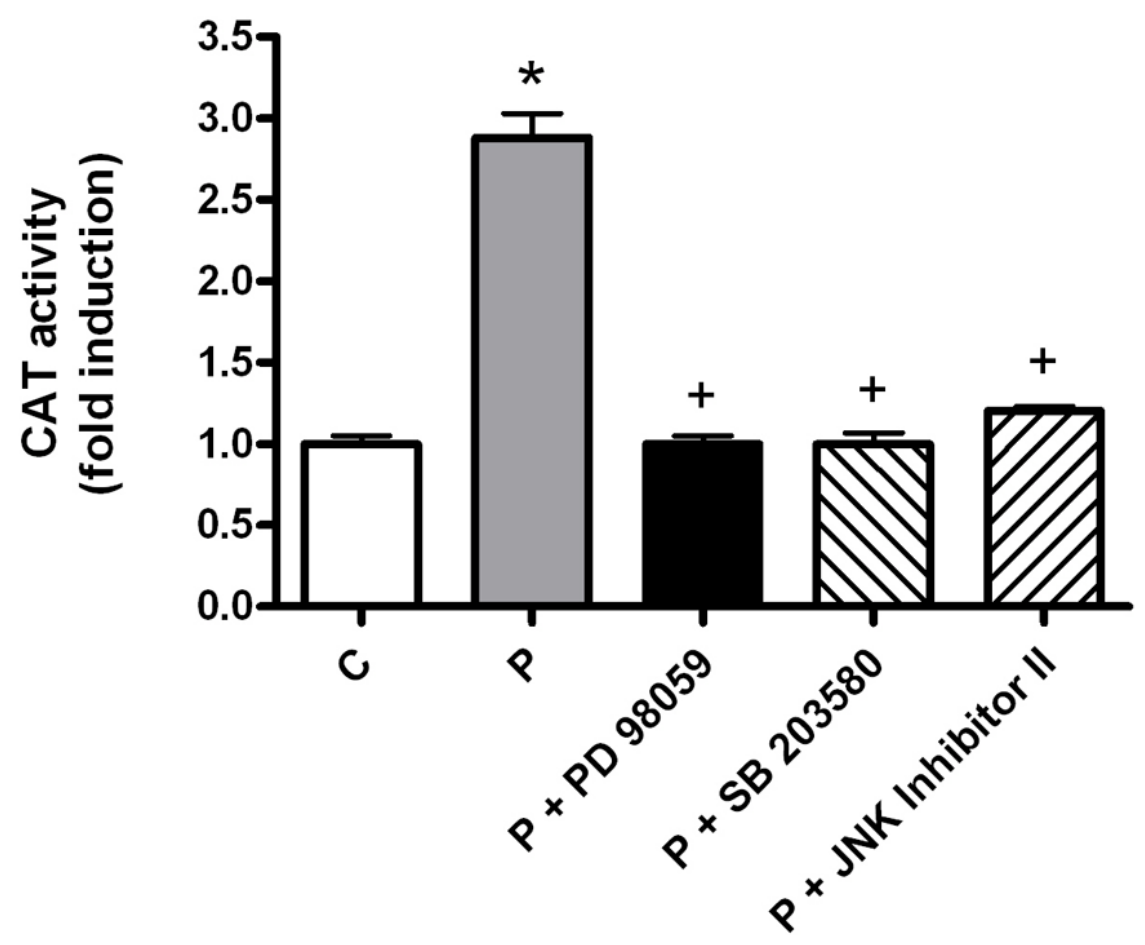

Figure 6 


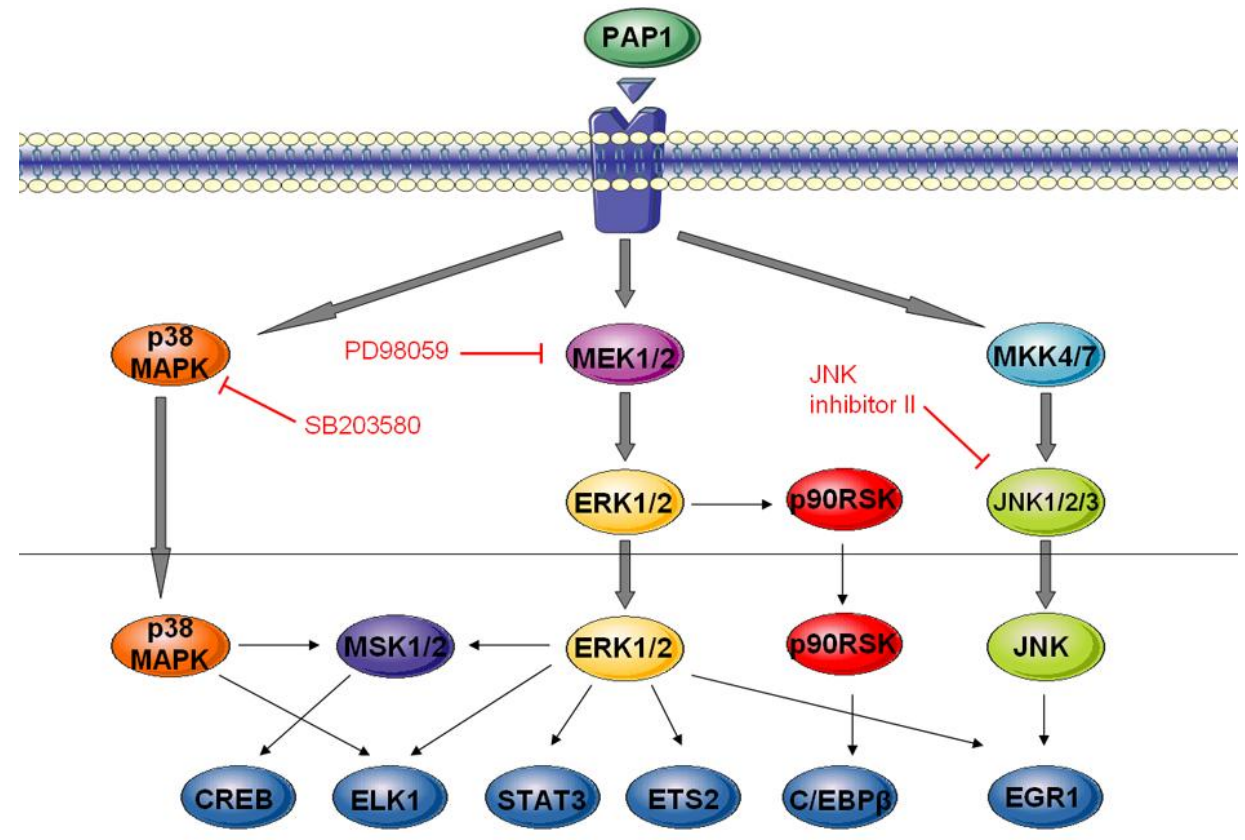

Figure 7 